\title{
THE ANALYSIS OF STRATEGIC PLANNING IN TRANSPORT
}

\author{
Margarita Išoraitè \\ Mykolas Romeris University of Lithuania, Ateities pr. 20, LT-08303 Vilnius, \\ E-mail:misorait@mruni.lt
}

Received 1 July 2005; accepted 4 January 2006

\begin{abstract}
Strategic planning is a process whish brings to life the mission and vision of an enterprise. The article analyses the following issues: 1 . Concepts of strategy. 2. Components of strategic planning. 3. The basis of strategic planning. 4. Formal strategic planning. 5. Tools used in strategy development. 6. Problems of strategic planning.
\end{abstract}

Keywords: transport strategic planning, strategic planning models, components of strategic planning.

\section{Introduction}

Strategic planning in business is like a map for a road rally driver. It is a tool which defines the routes to be taken that lead to the most likely probability of getting from where the business is to where the owners or stakeholders want it to go. And like a road rally, strategic plans meet detours and obstacles that call for adapting and adjusting as the plan is implemented. Strategic planning is a process that brings to life the mission and vision of an enterprise. A strategic plan, well crafted and of value, is driven from the top down; considers the internal and external environment around the business; is the work of the managers of the business; and is communicated to all the business stakeholders, both inside and outside the company. As a company grows and the business environment becomes more complex the need for strategic planning becomes greater. There is a need for all people in the corporation to understand the direction and mission of the business. Companies consistently applying a disciplined approach to strategic planning are better prepared to evolve as the market changes and different market segments require different needs for the products or services of the company. The benefit of the discipline that develops from the process of strategic planning leads to improved communication. It facilitates effective decision-making, better selection of tactical options and leads to a higher probability of achieving the owners' or stakeholders' goals and objectives. There is no one formula or process for strategic planning. There are, however, principles and required steps that optimize the value of strategic planning. The steps in the process described in this series of articles on strategic planning are presented below:

1. Current situation anglysis,

2. Segmentation anglysis,

3. Strength, weakness, opportunities, and threat anglysis,

4. Core competencies anglysis,

5. Key success factors,

6. Business unit strategy/business plan,

7. Balanced score card,

8. Evaluation.

The principles and steps of this process will be discussed in a series of articles following this introduction to strategic planning. The choice of the planning process that works best should be driven by the culture of the organization and by the comfort level of the participants. The strategic planning process must mirror the cultural values and goals of the company. There is a number of important steps to remember in the process of strategic planning. They include collecting a meaningful and broad data base, creatively thinking about differentiation, defining of gaps, assessing of core competencies and understanding of identifying critical resources and skills. An important distinction in the process is to recognize the difference between strategic planning, or the work being done, and strategic thinking, or the creative, intuitive input. The planning element involves data collection, goal setting, expectation definition and statement of direction. Strategic thinking includes the intuitive and creative elements. This thinking process takes into account and helps to leverage the values of the inter- 
nal culture of the business and external characteristics of the market. Strategic planning can be a challenging process, particularly of it is undertaken in a company for the first time. With patience and perseverance as well as a strong team effort the strategic plan can be the beginning of improved and predictable results for a company. At times when the business gets off track a strategic plan can help direct the recovery process. When strategic planning is treated as an ongoing process it becomes a competitive advantage and offensive assurance of improved day to day execution of the business practices. The use of an outside, independent facilitator can help in the process and in the development of a strategic plan. An outside resource can provide objectivity and serve as a "devil's advocate" as well as a sounding board for the management charged with plan development. In the final analysis the plan must have the authorship and ownership of the owner and the managers who must execute and follow the strategic plan. It must be their plan. The strategic plan, to be of real long-term value, must be treated as an ongoing business process. It must be reflective of the owners' mission and vision. It must evolve and change to reflect a changing market and economic conditions. It must be proactive to a competitive market and economic conditions. If those steps are followed, the strategic plan will institutionalize a culture of continuous improvement and disciplined change.

Strategic planning, when treated as the work in progress, rather than as a binder on a shelf, or a file in a computer, provides business with a real and lasting competitive advantage. It will help determine and direct the quality of relationships with suppliers, employees, unions, customers, and bankers. To get your business to where you desire it to be, start with determination and drive to develop a useful and living strategic planning process. Give it strong support and leadership from the top down. Develop and evolve it with participation and buy-in from the bottom up. Strategic planning is your company's road map to your vision.

\section{Concepts of strategy}

The concept of strategy has been adopted from the military and adapted for use in business. A review of what noted writers have to say about business strategy suggests that the adoption was easy because the adaptation was modest. In business, as in the military, strategy bridges the gap between policy and tactics. Strategy is a term that comes from the Greek strategia, meaning "generalship." In the military, strategy often refers to maneuvering troops into position before the en-emy is actually engaged. In this sense, strategy refers to the deployment of troops. Once the enemy has been engaged, attention shifts to tactics. Here, the employment of troops is central. Substitute "resources" for troops and the transfer of the concept to the business world begins to take form. Strategy also refers to the means by which policy is effected, accounting that a war is a continuation of political relations via other means. Given the centuries-old military origins of strategy, it seems sensible to begin our examination of strategy with the military view.

Strategy according to B. H. Liddell Hart. Basil H. Liddell Hart examines [1] wars and battles from the time of the ancient Greeks through World War II. He concludes that Clausewitz's definition of military strategy as "the art of the employment of battles as a means to gain the object of war" suffers from two serious flaws; first, this view of military strategy intrudes upon policy and, second, it makes battle the only means of achieving strategic ends. Liddell Hart observes [1] that Clausewitz later acknowledged these flaws and then points to what he views as a wiser definition of strategy set forth by Moltke: "the practical adaptation of the means placed at a general's disposal to the attainment of the object in view." In Moltke's formulation [1], military strategy is clearly a means to political ends. Concluding his review of wars, policy, strategy and tactics, Liddell Hart arrives at this short definition of military strategy: "the art of distributing and applying military means to fulfil the ends of policy." Deleting the word "military" from Liddell Hart's definition makes it easy to export the concept of strategy to the business world. This brings us to a person considered by many to be the father of strategic planning in the business world: George Steiner.

Strategy according to George Steiner. George Steiner (1979) [2] defines that planning is close to being a bible on the subject. Yet, Steiner does not bother to define strategy except in the notes at the end of his book. There, he notes that strategy entered the management literature as a way of referring to what one did to counter a competitor's actual or predicted moves. Steiner [2] also points out in his notes that there is very little agreement as to the meaning of strategy in the business world. Some of the definitions then in use to which he pointed include the following:

1. Strategy is that which top management does that is of great importance to the organization.

2. Strategy refers to basic directional decisions, that is, to purposes and missions.

3. Strategy consists of the important actions necessary to realize these directions.

4. Strategy answers the question: What should the organization be doing?

5. Strategy answers the question: What are the 
ends we seek and how should we achieve them?

Steiner [2] was writing in 1979, at roughly the midpoint of the rise of strategic planning. Perhaps the confusion surrounding strategy contributed to the demise of strategic planning in the late 1980s. The rise and subsequent fall of strategic planning brings us to Henry Mintzberg.

Strategy According to Henry Mintzberg. Henry Mintzberg (1994) [3], points out that people use "strategy" in several different ways, the most common being these four:

1. Strategy is a plan, a "how," a means of getting from here to there.

2. Strategy is a pattern in actions over time; for example, a company that regularly markets very expensive products is using a "high end" strategy.

3. Strategy is a position; that is, it reflects decisions to offer particular products or services in particular markets.

4. Strategy is a perspective, that is, vision and direction.

Mintzberg argues [3] that strategy emerges over time as intentions collide with and accommodate a changing reality. Thus, one might start with a perspective and conclude that it calls for a certain position, which is to be achieved by way of a carefully crafted plan, with the eventual outcome and strategy reflected in a pattern evident in decisions and actions over time. This pattern in decisions and actions defines what Mintzberg called "realized" or emergent strategy.

Mintzberg's typology [3] has support in the earlier writings of others concerned with strategy in the business world, most notably, Kenneth Andrews, a Harvard Business School professor and for many years the editor of the Harvard Business Review.

Strategy According to Kenneth Andrews. In the 1980 edition of his book, The Concept of Corporate Strategy, Andrews presents this lengthy definition of strategy [4]:

"Corporate strategy is the pattern of decisions in a company that determines and reveals its objectives, purposes, or goals, produces the principal policies and plans for achieving those goals, and defines the range of business the company is to pursue, the kind of economic and human organization it is or intends to be, and the nature of the economic and non-economic contribution it intends to make to its shareholders, employees, customers, and communities". Andrew's definition obviously anticipates [4] Mintzberg's attention to pattern, plan, and perspective. Andrews also draws a distinction between "corporate strategy," which determines the businesses in which a company will compete, and "business strategy," which defines the basis of competition for a given business. Thus, he also anticipated "position" as a form of strategy.
Strategy as the basis for competition brings us to another Harvard Business School professor, Michael Porter, the undisputed guru of competitive strategy.

Strategy According to Michael Porter. In a 1996 Harvard Business Review article and in his 1986 book, Competitive Strategy, Porter argues [5] that competitive strategy is "about being different." He adds, "It means deliberately choosing a different set of activities to deliver a unique mix of value." [5] In short, Porter argues that strategy is about competitive position, about differentiating yourself in the eyes of the customer, about adding value through a mix of activities different from those used by competitors. In his earlier book, Porter defines competitive strategy as "a combination of the ends (goals) for which the firm is striving and the means (policies) by which it is seeking to get there." Thus, Porter seems to embrace strategy as both plan and position.

Strategy According to Kepner-Tregoe In Top Management Strategy, Benjamin Tregoe and John Zimmerman, of Kepner-Tregoe, define [6] strategy as "the framework which guides those choices that determine the nature and direction of an organization." Ultimately, this boils down to selecting products (or services) to offer and the markets in which to offer them. Tregoe and Zimmerman urge [6] executives to base these decisions on a single "driving force" of the business. Although there are nine possible driv-ing forces, only one can serve as the basis for strategy for a given business. The nine possibilities are listed below:

- Products offered

- Production capability

- Natural resources

- Market needs

- Method of sale

- Size/growth

- Technology

- Method of distribution

- Return/profit.

It seems Tregoe and Zimmerman take the position that strategy is essentially a matter of perspec-tive [6].

\section{Components of strategic planning}

Three main components of strategic planning are: plan development, plan execution, and plan review. Many of the functional areas within these components are similar that all three require a team concept that is based on: ensuring the member's roles are defined, educating team members about the process, and using quality communication when interacting.

Plan development. Plan development is the first 
component of strategic planning. During this stage, the following steps should be completed.

1. Assess the enterprise history and significant accomplishments. Develop a history of the enterprise. List important milestones that brought the association to where it is today. In order to help visualize how the enterprise has changed over the years, include items where impact occurred in the enterprise operations, such as: hiring additional staff, upgrade computer hardware/software, changing processes significantly, raising dues, building additional facilities, rebuilding/renovating existing facilities, etc., by dates and quantities/dollars, as appropriate.

2. Assess the enterprise current status. Determine the enterprise current status by looking at such things as the state of the facilities, infrastructure of the operations, the financial statements, the demographics of the population, and so forth.

3. Evaluate the enterprise current governance structure. Review the operations to determine how responsibilities are assigned defining communications and authorities.

Examine policies, procedures, and desk guides available to determine the chain of command within the enterprise staff, within the board, and for oversight and communications between the staff or property management company and the board of directors. Critical is the point of contact for the staff or management company and the board, to preclude misunderstandings, duplications of effort, things falling through the cracks, etc.

4. Develop mission and vision statements. The vision statement is the image or state to which the association aspires. It emphasizes the dream of where the association will be at a specific time. The mission statement is the organization's purpose stated in a memorable phrase. In short, an enterprise mission statement describes the business it's in. It should be geared towards fulfilling the enterprise purpose and what it is intended to do with some specifics contained in the governing documents. Mission and vision statements should not be a list of goals.

5. Determine operating values called guiding principles. These values state the enterprise intentions and expectations. They are used to judge the enterprise policies and actions, as well as individual conduct. Enterprise should include values such as: the importance of customers and customer service; commitment to quality and innovation; the importance of honesty; integrity and ethical behavior; corporate citizenship; respect for the employee and duty the association has to its employees; and the importance of safety and protection of environment, etc.

6. Perform needs assessment. Determine the needs of the enterprise by analyzing the present state of the community, addressing any critical issues, and identifying the enterprise strengths, weaknesses, opportunities, and threats.

a. Determination of key result areas. Define five to ten areas in which the enterprise must be successful in order to accomplish its mission based on customer expectations.

b. Determine customer expectations. Determine the customer [members, suppliers, and employees] expectations of the enterprise as stakeholders. Group the expectations into five to ten key results areas.

7. Determine critical issues. List the critical issues faced by the enterprise that must be addressed for the enterprise to achieve its mission and vision based on an assessment of its strengths, weaknesses, opportunities, and threats.

a. Assessment of strengths, weaknesses, opportunities, and threats (SWOT).

i. Strengths. List the organizational attributes that promote the enterprise ability to meet its mission and vision.

ii. Weaknesses. List those organizational attributes that hamper the enterprise ability to meet its mission and vision. Some examples include inadequate technology or use of technology, lack core competency training, poor service, and so forth.

iii. Opportunities. List those factors, internal and external, that would enable the enterprise to meet its mission and vision. Some examples include technological advances in needed areas, consolidating functions, etc.

iv. Threats. List those factors, internal or external, that would hamper the enterprise from meeting its mission and vision. Some examples include high rate of foreclosures, drawn out worker strike, change in developer focus, etc.

8. Define the roles of key players. Who will be the key people responsible for each aspect of the strategic plan? Answer questions such as:

What level of control will the board have?

Is the manager going to be a proactive leader or an administrator?

Are the homeowners going to be active as committee members or are they going to be less involved?

9. Educate and communicate the plan. Without education and communication team members can neither perform their roles nor effectively interact with each other. Make sure that every player has the necessary documents and basic knowledge to perform effectively. Further ensure that each of the players communicates with each other - provide updates as necessary and always ask for others' input. Better to catch a potential problem earlier rather than later. In the event that there is a change in management, association boards should also be sure to communicates 
their strategic plans to the new manager, and revise it, if necessary. Also, if the strategic plan calls for specific management participation, make sure it is spelled out in the management contract.

10. Listen and take notes. During the strategic planning process it is important for all parties to actively listen and take notes. Many type - personalities, who may be involved with the enterprise at any level, will want to solve the community's issues quickly and efficiently. If they do this without listening to the board of directors, homeowners, and vendors, they may be executing a plan, but not a quality strategic plan.

11. Develop and prioritize long - range goals. Develop long-range goals to address the critical issues identified through the needs assessment; then prioritize those goals.

12. Develop short-term goals and action plans. Establish short - term goals and specific action plans along with scheduled completion dates.

13. Monitor the progress. Establish a monitoring process to assess the progress made on both short - term and long-range goals.

Plan Execution. Plan execution is the second phase of strategic planning. In this step an enterprise puts its plan into action through the allocation of resources. This step has three components:

1. Programs. Enterprise programs serve as blueprints for converting objectives into realities.

2. Procedures. Procedures are the specific sequence of tasks required to complete the programs.

3. Budgets. An enterprise should prepare budgets to fund programs. Instead, many develop programs are based on their budgets. Simply put, an enterprise should be strategy-driven, not budget-driven. If the plan development phase is put together well, then the plan execution phase is much easier. Many of the previously discussed items such as teamwork, roles, communication, and education are important and apply to the plan execution phase. Hold periodic meetings to review progress of short-term goals and plans. Without periodic meetings and reviews the community will not move forward and achieve its goals. Lastly, adaptability is crucial to the plan execution phase since all plans will have flaws. If the team members are not adaptable, there may be simple issues that will not be resolved in a reasonable manner and the community will suffer.

Plan Review. Plan review is required constantly to improve the plan and ensure its execution. Part of the plan review occurs naturally when there's board turnover, a new homeowner, or changes in the law. In addition, plan review needs to be scheduled to ensure the plan is meeting the community's goals. This can be achieved through surveys, management review conferences, or discussions at meetings. If the com- munity fails to update the plan, the plan will eventually fail the community. Industry experts suggest that enterprises and their managers review their strategic plans annually and completely overhaul their strategic plans every three to five years.

Use of a Consultant. An outside consultant or professional facilitator brings impartiality, pointed questions and the facilitation skills needed to balance differences of opinion. Enterprise should be aware that consultants will take different approaches to strategic planning as no one, right way exists. While hiring a consultant can be expensive, he or she will greatly accelerate the enterprise learning curve and help to ensure that the strategic planning process will complete a full cycle. If budgetary restraints do not allow for such assistance, enterprise may want to consider using a consultant for the initial sessions where an objective assessment of the enterprise current position is necessary.

\section{The basis of strategic planning}

Strategic planning is more than ensuring your association will remain financially sound and be able to maintain its reserves - it's projecting where your enterprise expects to be in five, ten, or fifteen years and how your enterprise will get there. It is a systematic planning process involving a number of steps that identify the current status of the enterprise, including its mission, vision for the future, operating values, needs (strengths, weaknesses,opportunities, and threats), goals, prioritized actions and strategies, action plans, and monitoring plans. Strategic planning is the cornerstone of every common - interest community. Without strategic planning the community will never know where it is going - much less knows if it ever gets there. An important concept of strategic planning is the understanding that in order for the community to flourish, everyone needs to work to ensure the team's goals are met. Team members include all enterprise, the board of directors, professional management - whether onsite or through a management company - and various service professionals such as accountants and reserve professionals. This team needs to work as a collective body to be successful. A part of the team concept is the establishment of roles for team players. Teams usually perform poorly, if everyone or no one is trying to be the quarterback.

\section{Formal strategic planning}

A crucial benefit of the formal planning process is its built-in guarantee that things will not just happen; it ensures that control will be exerted to help the 
organization retain its strategic focus. By forcing the organization to analyze and identify its strengths and weaknesses, its core competencies, the threats that it faces and the opportunities it is qualified to exploit, formal strategic planning strengthens its understanding of who it is and what it is equipped to accomplish. Plans made on an ad hoc basis by people within a particular function or business unit will inevitably reflect the concerns of those people and that business. When senior managers formulate strategy, however, they are more likely to be objective and to see the larger picture. They also have more facts at their disposal and can gather information from all areas of the organization. Because they have the tools and the training to sift through data; because they can interpret it, weigh up its relative importance, and arrive at the decisions based on systematic assessment, senior managers are uniquely qualified to evaluate various strategies' likelihood of success. Another advantage of a deliberate, linear process is that it allows the organization to arrive at a clear definition of where it wants to go, how it plans to get there, and how it can measure its progress towards the goal. Thinking through how you can differentiate yourselves, how you can win, what you are uniquely qualified to do - and what you do not want to do - can only be beneficial to the company as it goes forward. Who would choose to set out on a journey without a map? You cannot get to where you are going if you do not know where it is. The formal plan is a kind of a road map to be consulted along the way. Finally, even in a turbulent world, having such a road map will provide a context for dealing with the unexpected as it arises. In order to respond effectively to change, companies need a clear sense of their capabilities and the kinds of resources they can draw on when they are required to adapt to changing circumstances.

\section{Tools used in strategy development}

There are several key tools that can be used during the strategy development and strategic planning.

* Environmental scanning (or competitive intelligence) is a rigorous approach to collecting, analyzing and communicating information about competitors ${ }^{6}$ activities, market changes that are occuring, changes related to the supply of raw materials and other issues that could affect strategic directions. Such information is legally and ethically obtained from a wide range of sources using formalized techniques and can be factored into decision making.

* Planning and forecasting scenario helps planners deal with the uncertain future by providing a mechanism for envisioning a range of future scenarios, examine the possible impacts of them, develop a com- mon view of the changing world, and prepare for it.Scenarios sometimes are best used not as a basis for strategy, but as a way to improve how managers do it.

* Capital planning and budgeting is the process by which unit managers propose individual projects up the hierarchy for approval. This usually involves cost/ benefit assessment for each proposal, allowing senior managers to campare and rank them and accept only as many as the capital funding allows.

* Portfolio analysis is a technique similar in some respects to capital budgeting, but usually on the business rather than project level used to examine the relative value of various businesses, subsidaries, or other units within a company, and to determine if a balance „mix” has been achieved. This helps corporate-level planners to reach better understanding of the competitive position of the overall portfolio of businesses, to suggest strategic alternatives for the businesses, to understand the value of acquiring new businesses, and, overall, to develop priorities for resource allocation. Often this is done through the use of portfolio matrices, a set of graphic displays that help managers visualize the portfolio along two dimensions: usually an external dimension related to the overal attractiveness of the industry, and an internal one that relates to the strength of the business within that industry (Hax and Majluf, 1996) [7].

* Roadmapping is a technique used by many companies (Willyyard and McClees, 1987) [8] to plan new product development.

* Game theoretic modeling is the analysis of rational behavior in situation involving interdependence of outcomes, a technique sometimes used to improve development of a competitive strategy by addressing such microeconomic issues as the importance of first - mover advantages and the role of commitment, reputation formation and exploitation, signaling, and the strategic control of information (Saloner, 1994) [9]. Game theory involves looking forward and reasoning backward to fomulate a strategy that has the best chance of leading to the desired outcome in situations where that outcome is dependent upon the decisions of the others as well as one's own (Brandenburger and Nelebuff, 1995) [10]. It provides a way to analyze key strategic decisions concerning cooperation, coordination and differentiation (Kay, 1995 [11]). Game theory has been found more useful as a metaphorical tool that can provide insights into patterns of behavior likely to occur under different circumstances than as a literal analytic model (Kay, 1995) [11].

* Stakeholder analysis and engagement is related to game theory that it emphasizes the importance of identifying, understanding, building relationship with, and satisfying key stakeholders, both inside and out- 
side the boundaries of the organization. Stakeholder analysis involves understanding of the interests and concerns of the various stakeholders realtive to the potential strategies and activities of the organization. Stakeholder analysis is coupled with an effort to engage stakeholders in a way that builds relationships, meets disclosure of information requirements in a positive way and maximizes the potential to motivate behavior beneficial to the organization.

* Decision science and decision analysis. The theoretical foundations of decision analysis are a set of axioms that imply that the desirability of alternative courses of action depends on the likelyhood of possible outcomes and the preferences for those outcomes. Likelihood is estimated using probability distrubutions and desirability is measured using utility functions. Probabilities and utilities are used to calculate the expected utility of each alternative. Alternatives with higher expected utilities should be preferred.

\section{Problems of strategic planning}

Tightly controled organizations with high reliance on formalized procedures and a passion for consistency may lose the ability to innovate and may hence become less successful. Some people believe strategy itself is deleterious to an organization's success. But focusing on strategy does not necessarily have to prevent creativity and felxibility. Hamel (2000) states [12] that development of innovative strategic competency is the critical factor for ensuring future organizational success.

Most criticism has focused on the formalized, strategic planning processes that Mintzberg (1996) [13] classifies as the planning school approach. This criticism can be summarized as follows:

* Products of planning often aren't used.

* Planning processes can dominate the staff. Methodologies can become very elaborate and time consuming with too much emphasis on analysis and too little on true strategic insights.

* The implementers are often excluded from the process. New organizations are sometimes created just to conduct the planning, often cutting executives out of the strategy development process.

* Planning processes often fail to develop true strategic choices. Planners sometimes adopt the first strategy that meets certain basic conditions in an acceptable manner. They make no real effort to search for or analyze an array of strategy alternatives before making a decison.

* Forecasts are invariably wrong. Strategic planning requires stability during and predictability following strategy making. Planning cannot do much than extrapolate the present trends and hope for the best.

* Hard data used in strategic planning lack the richness needed to make strategic decisions. The strategic planning system is supposed to be detached and objective and relies on detailed facts about the organization and its context. However hard information is often limited in scope and fails to encompass important non - economic and non - quantitative factors.

* Innovation cannot be institutionalized. Strategic planning is not always viewed as an aid to strategic thinking or strategy making, but as the replacement for intuition and creative thinking.

* Strategic planning is not strategy making. Mintzberg (1998) stated that planning, rather than providing new strategies, could not proceed without their prior existence. Strategic planning has been misnamed. It should have been called strategic planning.

\section{Conclusions}

1. Strategic planning is one of the most respected and valued management tools for turning organizational dreams into reality. It is defined as the process by which organizations determine and establish longterm directions, formulate and implement strategies to accomplish long-term objectives while taking into account relevant internal and external environmental variables.

2. Strategy has been borrowed from the military and adapted for business use. In truth, very little adaptation is required. Strategy is about means. It is about the attainment of ends, not their specification. The specifica-tion of ends is a matter of stating those future conditions and circumstances towards which effort is to be devoted until such time as those ends are obtained. Strategy is concerned with how you will achieve your aims, not with what those aims are or ought to be, or how they are established. If strategy has any meaning at all, it is only in relation to some aim or end in view.

3. Strategy is one element in a four-part structure. First is the ends to be obtained. Second is the strategies for obtaining them, the ways in which resources will be deployed. Third is tactics, the ways in which resources that have been deployed are actually used or employed. Fourth and last are the resources themselves, the means at our disposal. Thus it is that strategy and tactics bridge the gap between ends and means.

4. Establishing the aims or ends of an enterprise is a matter of policy and the root words there are both Greek: politeia and polites - the state and the people. Determining the ends of an enterprise is mainly a matter of governance not management and, conversely, achieving them is mostly a matter of manage- 
ment not governance. Those who govern are responsible for seeing that the ends of the enterprise are clear to the people who people that enterprise and that these ends are legitimate, ethical and that they benefit the enterprise and its members. Strategy is the joint province of those who govern and those who manage. Tactics belongs to those who manage. Means or resources are jointly controlled. Those who govern and manage are jointly responsible for the deployment of resources. Those who manage are responsible for the employment of those resources-but always in the context of the ends sought and the strategy for their achievement. Over time, the employment of resources yields actual results and these, in light of intended results, shape the future deployment of resources. Thus it is that "realized" strategy emerges from the pattern of actions and decisions. And thus it is that strategy is an adaptive, evolving view of what is required to obtain the ends in view.

\section{References}

1. Liddell Hart, B. H. Strategy: The indirect approach. London: Faber and Faber Limited, 1967.

2. Steiner, G. Strategic planning. New York: Free Press, 1979.

3. Mintzberg, H. The rise and fall of strategic planning. New York: Free Press, 1994.

4. Kenneth, A. R. The concept of corporate strategy. IL: Dow Jones-Irwin, 1980.

5. Porter, M. What is strategy? Harvard Business Review, Nov-Dec, 1996, p. 61-78.

6. Tregoe, B. et al. Top management strategy. New York: Simon \& Schuster, 1980.

7. Hax, A. C.; Majlux, N. S. The strategy concept and process: a pragmatic approach. NJ: Prentice Hall, 1996.

8. Willyard, C. H.; McClees, C. W. Motorola's technology roadmap process. Research Management, Sept/Oct, 1987, p. 13-19.

9. Garth, S. Game theory and strategic management: contribution, applications and Limitations. In: Fundamental issues in strategy: a research agenda. Boston: Harvard Business School Press, p. 155-195.

10. Branderburger, A. M.; Nelebuff, B. J. The right game: use game theory to shape strategy. Harvard Business Review, July - August, 1995, p. 57-71.

11. John K. Why firms succeed. New York: Oxford University Press, 1995.

12. Hamel, G. Leading the revolution. Boston: Harvard Business School Press, 2000.

13. Mintzberg, H.; Quinn, J. B. The strategy process: concepts, contexts, cases. NJ: Prentice Hall, 1996. 